\title{
Mortality Ascertainment of Women Veterans: A Comparison of Sources of Vital Status Information, 1979-2002
}

\author{
Dr. Lara S. Savas ${ }^{1}$, Dr. Deborah J. del Junco ${ }^{2}$, Dr. Lori A. Bastian ${ }^{3}$, and Dr. Sally W. \\ Vernon 4 \\ ${ }^{1}$ Department of Family and Community Medicine, Baylor College of Medicine \\ ${ }^{2}$ Center for Clinical and Translational Sciences, University of Texas Health Science Center at \\ Houston \\ ${ }^{3}$ Center for Health Services Research in Primary Care, VA HSR\&D Center of Excellence, Durham \\ Veterans Affairs Medical Center, 508 Fulton Street (152), Durham, NC; Duke University \\ ${ }^{4}$ Division of Health Promotion and Behavioral Sciences, University of Texas-Houston School of \\ Public Health
}

\begin{abstract}
Background-To support health research on the unique cohort of women with a history of military service, this study assessed the completeness of mortality ascertainment for Texas women veterans in Department of Veterans Affairs (VA) and non-VA databases.

Methods-We examined female-veteran-specific mortality ascertainment comparing the VA Beneficiary Identification and Records Locator Subsystem Death File (BIRLS DF), VA Patient Treatment Files (PTF) and Social Security Administration-Death Master File (SSA-DMF) with Texas death certificate data. Databases were deterministically crosslinked using female sex and social security numbers. Deterministic and probabilistic linkage methods were also compared.
\end{abstract}

Results-Of 6,297 decedents identified by death certificates, SSA-DMF, BIRLS DF, and PTF databases identified 97.5 percent collectively and 94 percent, 77 percent, and 5 percent individually. Compared with Texas death certificates, sensitivity of VA and SSA databases improved with increasing age.

Conclusions-This study highlights that although the VA and SSA administrative databases have less complete ascertainment for younger decedents, combined these electronic databases provide nearly complete ascertainment for women veterans.

Challenges related to large female-specific cross-linkage studies are explored and a need to examine methods for female-specific health research studies in the general population is identified.

\section{Keywords}

Administrative Databases; Death Certificates; Female; Mortality; Veterans

\section{Introduction}

As the largest integrated health care system in the United States (U.S.), ${ }^{1}$ the Department of Veterans Affairs (VA) maintains centralized electronic databases with national coverage,

Corresponding author: Lara S. Savas, Ph.D., Department of Family and Community Medicine, Baylor College of Medicine, 3701 Kirby Dr. Suite 600, Houston, Texas 77098-3926, Tel: 713-798-9181, Fax: 713-798-7940, savas@ bcm.tmc.edu. 
providing opportunities for efficient cross-linkage for a variety of research studies. In addition, during the past three decades, there has been a shift in the military population with increasing representation of women enlistees. The need for augmented research focused on femalespecific veteran health issues has made women veteran's health research a priority area for investigator-initiated research by the U.S. Department of Veterans Affairs Health Services Research and Development (VA HSR\&D). ${ }^{11}$

Tracking mortality in women with a history of military service is an important indicator necessary to understand long-term health effects of military service and deployment overseas. However, previous studies that have examined the completeness and accuracy of mortality status in administrative databases commonly used to ascertain vital status for veterans have been largely restricted to male veterans who use the VA health care system. ${ }^{12-19}$ The overall goal of this study is to provide the first female-specific assessment of the completeness of death information for all female veterans residing in Texas, regardless of whether they have used VA health services, by comparing VA administrative databases and the Social Security Administration -Death Master File (SSA-DMF), with Texas death certificates as reported to the National Death Index. Death certificates ${ }^{20}$ and the National Death Index are considered the gold standard for mortality ascertainment in the U.S. ${ }^{15}$

\section{Methods}

To identify Texas female veterans who died between 1979 and 2002, the U.S. National Registry of Women Veterans (NRWV) was deterministically cross-linked with Texas death certificates records (Texas mortality database), the VA Beneficiary Identification and Records Locator Subsystem Death File (BIRLS DF), the VA Patient Treatment File (PTF), and the Social Security Administration-Death Master File (SSA-DMF) on exact Social Security numbers and female sex. The subset of Texas decedents identified using the Texas mortality database (considered the gold standard for identifying mortality in this study) served as the basis for comparison with VA sources of vital status data.

The NRWV includes approximately 1.4 million records of women who served in the active U.S. military and were discharged between January 1, 1942 and 1997, regardless VA healthcare enrollment. The BIRLS DF, the largest VA source of death information, records fact-of-death information for decedent veterans who were VA beneficiaries or whose survivors applied for death benefits. ${ }^{21}$ Since October 1991, the PTF has recorded patient deaths that occur while hospitalized at a Veteran Health Administration (VHA) facility or after discharge if a survivor informs the hospital of the event. ${ }^{20}$ The VA maintains a copy of the SSA-DMF, which contains death notices for enrollees in the U.S. social security program. ${ }^{22}$ Differences in death ascertainment across the Texas mortality database, BIRLS DF, PTF, and SSA-DMF were examined by age using sensitivity, specificity and the Kappa coefficient for inter-rater agreement.

This research was conducted as part of a National Cancer Institute/ National Institute of Health RO3-funded research study, which was approved by institutional review boards of the University of Texas Health Science Center at Houston, the Texas Department of State Health Services, Texas A\&M University System Health Science Center, and the Durham Veterans Affairs Medical Center.

\section{Results}

Overall, aside for median year of death as ascertained by the PTF, there were no meaningful differences across databases regarding the demographic composition of Texas female veteran decedents ascertained on the NRWV (Table 1). A total of 6,297 Texas female veteran decedents 
were identified by the Texas mortality database. Of those, 97.5 percent were identified by the combination of SSA-DMF, BIRLS DF, and PTF, and 94 percent, 77 percent and 5 percent by the respective individual databases. Using the Texas mortality database as the standard for comparison, sensitivity of VA and SSA databases improved with increased age (Table 2).

\section{Conclusions}

Our results are consistent with sensitivity rates reported in 2006 by Sohn and colleagues ${ }^{18}$ among primarily male (95 percent) VA-users, suggesting parity in completeness of death records for female veterans. Sohn and colleagues ${ }^{18}$ reported the BIRLS DF was 77.4 percent complete, the SSA-DMF 92.1 percent complete (compared with 94 percent in our populationbased study), and the VHA Medical SAS Inpatient Datasets (previously referred to as the PTF dataset), were 12 percent complete (higher than the 5 percent found in our population that included non-VA users). Subsequent to the study by Sohn and colleagues ${ }^{18}$, a VA database that combines death dates from the VA BIRLS DF, SSA-DMF, Medicare Vital Status File and Medical SAS Inpatient Datasets (e.g., the PTF), was made available as the VA Vital Status Files. $^{24}$

Findings based on this Texas cohort of women with a history of military service indicated that although less complete for decedents 44 years of age and younger, the combined VA and SSA mortality databases provide nearly complete death ascertainment. The age differences in mortality ascertainment most likely reflect the purpose of the BIRLS DF and SSA-DMF to track vital status of their older beneficiary populations, and the PTF to track survival among VA in-patient populations. In contrast, state-based mortality data are intended for public health research, thus data are ascertained regardless of age and beneficiary status.

A potential limitation of this study may be the use of deterministic linkage techniques using SSNs and female sex. We included female-sex as a matching criterion to help mitigate the potential problem of SSNs on death certificates belonging to women veterans' decedent spouses, especially among older (85+ years) women decedents ${ }^{23}$. To the extent that female decedents were missing SSNs, our study results would be affected by under-ascertainment of veteran deaths. Another potential limitation that may affect our linkage results is the possible inclusion of inaccurately recorded SSNs by either database due to data entry errors. To help prevent matching on erroneous SSNs, a computer algorithm was used to identify invalid SSNs on the NRWV before cross-linking the database with Texas death certificate data.

The potential bias related to variability in accuracy of SSNs on different databases may be further obscured for women due to last name changes. To address the challenge of evaluating a 'true match' for female veteran linkage studies, an extension of this research using a probabilistic matching algorithm in the same female veteran cohort was subsequently completed. Probabilistic techniques enable cross-linkage of records with imperfect matching on some or all identifying variables. A total of 5,801 matching records were identified using both deterministic and probabilistic techniques. An additional 496 matching records were identified uniquely by deterministic linkage methods and 235 matching records were identified uniquely by probabilistic linkage methods. The increase in ascertainment using deterministic methods may be due to a discrepancy between missing identifiers (e.g., birth dates or name), which were required by probabilistic methods to confirm a matching SSN. The 235 matches missed by deterministic methods were likely due to errors in the SSN (e.g., transpositions of numbers in the SSN or single digit loss). Assuming that deaths ascertained by either method are true matches, deterministic linkages identified $96.4 \%$ and probabilistic linkages identified $92.4 \%$ of all female veteran deaths. Further research regarding the challenges related to femalespecific cross-linkage studies is needed and would have important implications for any femalespecific cohort study using cross-linkage techniques. Thus, in addition to promoting research 
among women veterans, methodological insights gained from women veteran studies also have the potential to enhance research methods for female-specific health research studies in the general population.

Lastly, this study did not examine cause of death information, which is critical in retrospective (or historical) cohort mortality studies. However, understanding the accuracy of vital status information in female veteran populations has multiple benefits. First, vital status information facilitates health service and epidemiologic research that includes mortality as an outcome or requires the information to track subjects that are lost to follow-up. Second, vital status information helps to identify known decedents or survivors in the veteran sampling frame before using more expensive resources to obtain cause of death or updated contact information.

In summary, compared with the Texas mortality database, the SSA-DMF provides the most complete database source of vital status data maintained by the VA for health studies conducted among women veterans. Neither the BIRLS DF nor the PTF alone should be relied upon to identify female veteran decedents. These findings suggest completeness of female fact-ofdeath data are similar to male veterans on the VA BIRLS DF, SSA-DMF, and PTF, which are included in the centralized VA Vital Status files. ${ }^{24}$ Researchers interested in specific causes of mortality may follow the strategies used in this study (using State mortality data) to significantly reduce research costs of large-scale linkages with the NDI (to ascertain cause of death).

\section{Acknowledgments}

Grants: This research was supported by the A Cancer Study among Female Veterans in Texas, 1979-2002 grant R03CA10351-01A2 from the National Institute of Cancer. Preparation of this article was also supported in part by the Behavioral Science Education Cancer Prevention and Control training grant 2R25CA57712-11 from the National Cancer Institute (L.S.S.) and the Women Veterans and Breast Cancer Screening grant R01CA076330 from the National Cancer Institute (S.W.V. D.J.dJ, and L.A.B.). L.S.S. is currently supported fulltime by the National Research Service Award 5 T32 HP10031-09 from the Health Resources and Services Administration.

\section{References}

1. Public Health Strategic Healthcare Group (PHSHG) Website: The U.S. Department of Veterans Affairs; 2007

2. U.S. Department of Defense. Women Play Crucial Role in Nation's Defense: Executive summary "Women in Defense --DoD Leading the Way,". [11/27/2007]. http://www.defenselink.mil/speeches/speech.aspx?speechid=891

3. Blair A, Zahm SH, Silverman DT. Occupational cancer among women: research status and methodologic considerations. American Journal of Industrial Medicine Jul;1999 36(1):6-17. [PubMed: 10361581]

4. Carpenter L, Roman E. Cancer and occupation in women: identifying associations using routinely collected national data. Environmental Health Perspectives May;1999 107 2:299-303. [PubMed: 10350514]

5. Garcia AM. Pesticide exposure and women's health. American Journal of Industrial Medicine Dec; 2003 44(6):584-594. [PubMed: 14635235]

6. Gunnarsdottir HK, Kjaerheim K, Boffetta P, Rafnsson V, Zahm SH. Women's Health: Occupation, Cancer, and Reproduction. A conference overview. American Journal of Industrial Medicine Jul;1999 36(1):1-5. [PubMed: 10361580]

7. Hatch M, Moline J. Women, work, and health. American Journal of Industrial Medicine Sep;1997 32 (3):303-308. [PubMed: 9219662]

8. Kogevinas M, Zahm SH. Introduction: epidemiologic research on occupational health in women. American Journal of Industrial Medicine Dec;2003 44(6):563-564. [PubMed: 14635232] 
9. Messing K, Punnett L, Bond M, et al. Be the fairest of them all: challenges and recommendations for the treatment of gender in occupational health research. Am J Ind Med Jun;2003 43(6):618-629. [PubMed: 12768612]

10. Niedhammer I, Saurel-Cubizolles MJ, Piciotti M, Bonenfant S. How is sex considered in recent epidemiological publications on occupational risks? Occup Environ Med Aug;2000 57(8):521-527. [PubMed: 10896958]

11. VA Health Services Research and Development (HSR\&D). VA Health Services Research and Development Service Program Announcement. HSR\&D Priorities for Investigator -Initiated Research -Fiscal Year 2006. [July 12, 2006]. http://www.research.va.gov/funding/solicitations/docs/HSRD_Priorities_2006.pd f

12. Boyle CA, Decoufle P. National sources of vital status information: extent of coverage and possible selectivity in reporting. American Journal of Epidemiology Jan;1990 131(1):160-168. see comment. [PubMed: 2403466]

13. Dominitz JA, Maynard C, Boyko EJ. Assessment of vital status in Department of Veterans Affairs national databases. comparison with state death certificates. Annals of Epidemiology Jul;2001 11(5): 286-291. [PubMed: 11399441]

14. Fisher SG, Weber L, Goldberg J, Davis F. Mortality ascertainment in the veteran population: alternatives to the National Death Index. American Journal of Epidemiology Feb 1;1995 141(3):242250. [PubMed: 7840098]

15. Lorenz KA, Asch SM, Yano EM, Wang M, Rubenstein LV. Comparing strategies for United States veterans' mortality ascertainment. Popul Health Metr Feb 24;2005 3(1):2. [PubMed: 15730553]

16. Page WF, Braun MM, Caporaso NE. Ascertainment of mortality in the U.S. veteran population: World War II veteran twins. Military Medicine Jul;1995 160(7):351-355. [PubMed: 7659242]

17. Page WF, Mahan CM, Kang HK. Vital status ascertainment through the files of the Department of Veterans Affairs and the Social Security Administration. Annals of Epidemiology Mar;1996 6(2): 102-109. [PubMed: 10068251]

18. Sohn MW, Arnold N, Maynard C, Hynes D. Accuracy and completeness of mortality data in the Department of Veterans Affairs. Population Health Metrics 2006;4(1):2. [PubMed: 16606453]

19. Page WF. VA mortality reporting for World War II army veterans. Am J Public Health Jan;1992 82 (1):124-125. [PubMed: 1536319]

20. Cowper DC, Kubal JD, Maynard C, Hynes DM. A primer and comparative review of major US mortality databases. Annals of Epidemiology Oct;2002 12(7):462-468. [PubMed: 12377423]

21. Department of Veteran Affairs (VA), Health Services Research and Development Service Resource Center. VA Information Resource Center (VIRec). [9/25/2006]. http://www.virec.research.va.gov/DataSourcesName/DataNames.htm

22. U.S. Department of Commerce Technology Administration. Social Security Administration's Death Master File. [7/10/2006]. http://www.ntis.gov/products/ssa dmf.asp?loc=4-0-0

23. Hill ME, Preston SH, Rosenwaike I. Age reporting among white Americans aged 85+: results of a record linkage study. Demography May;2000 37(2):175-186. [PubMed: 10836175]

24. Arnold, N.; Sohn, MW.; Maynard, C.; Hynes, DM. Edward Hines, Jr. VA Hospital. VIReC Technical Report 2: VANDI Mortality Data Merge Project. Hines, IL: VA Information Resource Center; 2006. 


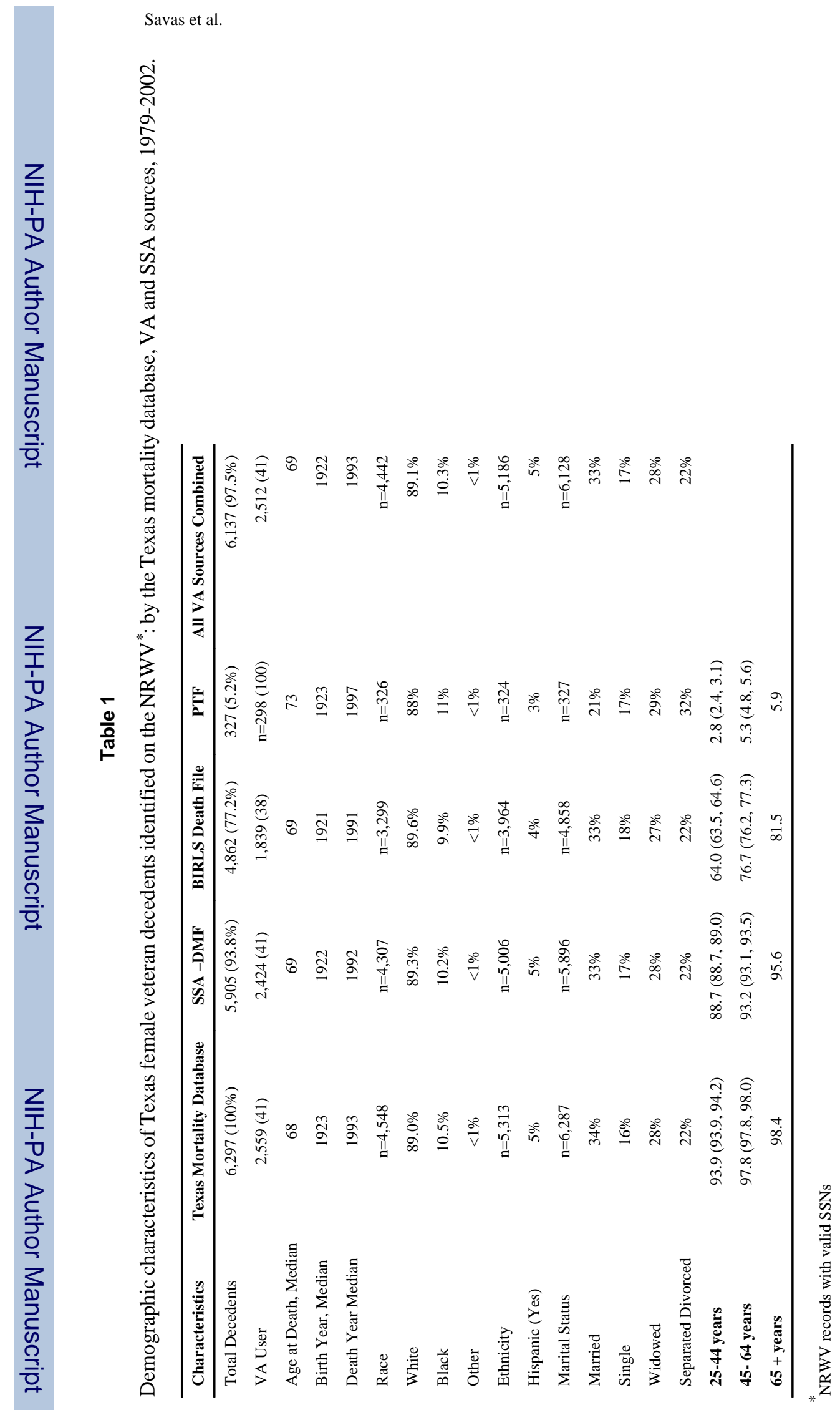

Page 6 


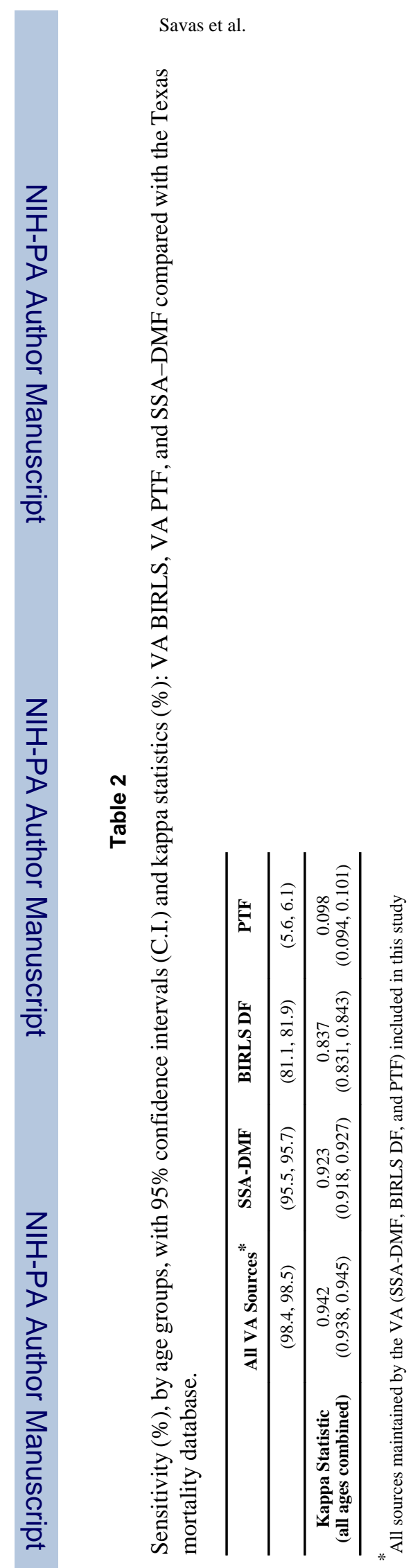

Page 7 